\title{
Facial reflex examination for assessment of trigeminal nerve involvement in pituitary fossa tumours
}

\author{
OLOF BYNKE
}

\author{
From the Department of Neurosurgery, University Hospital, Linköping, Sweden
}

SUMMARY Sixteen patients with pituitary fossa tumours with different intrasellar extension have been studied by facial reflex examination, a neurophysiological test for the trigemino-facial pathway. Impaired transmission along the reflex path was shown in patients with proved encroachments on the flexible walls of the cavernous sinuses, but with no tumour spread to the brain stem and facial nerve. The findings were consistent with a subclinical involvement of the first trigeminal division. Tumour removal resulted in recovery in nerve conduction. It is concluded that facial reflex examination is a valuable test for detecting cavernous sinus involvement in pituitary fossa tumours.

Encroachments made by a pituitary tumour on the flexible walls of the cavernous sinuses are often evident only at the time of operation upon the tumour. Sella radiographs show the bone walls of the pituitary fossa but an invasive radiographic technique or the later generation of computed tomographic (CT) scanners are required to delineate the lateral borders of the sella..$^{-4}$

Mechanical stimulation by tapping the supraorbital region evokes a double response $e^{5}$ by activation of skin receptors. ${ }^{6} \mathrm{~A}$ test based on the mechanically evoked early response (R1) has been developed and called facial reflex examination. ${ }^{7}$ It has been studied in normal subjects and in patients with space-occupying lesions compressing the trigemino-facial reflex path at different sites. The aim of the present study is to evaluate the effects on the trigeminal nerve in patients with laterally extending sellar tumours with no spread to the brain stem and facial nerves.

\section{Methods}

Sixteen patients, five women and 11 men aged $22-68$ years (mean age 44 ), with pituitary fossa tumours were studied (table 1). Clinical manifestations and biochemical evidence of pituitary hypersecretion were present in eight patients. Eight patients had nonfunctioning pituitary fossa lesions. Endocrine evaluation showed pituitary insufficiency in two

Address for reprint requests: Dr Olof Bynke, Department of Neurosurgery, University Hospital, S-581 85 Linköping, Sweden.

Received 17 February 1983 and in final revised form 19 December 1984. Accepted 12 January 1985 patients (table 1). Both were receiving hormonal substitution therapy before their admission for surgery; in Patient 15 with cortisol and in Patient 16 with cortisol and thyroxin. Chiasmal symptoms were present in two patients (Patients 9 and 16). Both had bitemporal visual field defects and visual acuity was impaired in one of them (Patient 9). Ptosis and abducent nerve palsy had been present on the left side in Patient 15 but there was normal motility on his admission two months later. There were no signs or symptoms of involvement of the trigeminal nerve in any patient.

The neuroradiological evaluation included sellar radiography with tomography in anterior-posterior and lateral planes and CT in all patients. These examinations were supplemented by pneumography in eight patients, carotid angiography in four and orbital phlebography in two patients.

Fourteen patients underwent transsphenoidal surgery, similar to that described by Hardy. ${ }^{8}$ Two tumours (in Patient 9 and 16) were approached by the intracranial subfrontal route. Histological examinations showed pituitary adenomas in 15 patients and a craniopharyngioma in Patient 16. Surgery did not result in any additional pituitary insufficiency.

Classification of tumour extension and intrasellar pressure The modfication of Hardy's classification system ${ }^{4}$ was used to grade the tumours on the basis of radiographic and intraoperative findings (table 1). Neuroradiographical examinations did not show spread of the tumour to the brain stem or the apex of the petrous bone in any patient. At surgery most tumours were proved to be asymmetrically located within the sellae and the encroachments on the flexible walls to the cavernous sinuses were carefully disclosed. Operation offered also an opportunity to study the intrasellar pressure and it was graded in three categories on the basis of the intraoperative findings: (a) 
Table 1 Summary of 16 patients with pituitary fossa lesions

\begin{tabular}{|c|c|c|c|c|}
\hline Patient No & Age (yr) & $\operatorname{Sex}$ & Preoperative endocrine condition* & Grade of tumour $\dagger$ \\
\hline 1 & 30 & $\mathbf{M}$ & Acromegaly; basal GH level $40 \mu \mathrm{g} / 1$ & IIO \\
\hline 2 & 41 & $\mathbf{M}$ & Acromegaly; basal GH level $10 \mu \mathrm{g} / 1$ & IIO \\
\hline 3 & 55 & $\mathrm{~F}$ & Acromegaly; basal GH level $30 \mu \mathrm{g} / 1$ & IIA \\
\hline 4 & 58 & $\mathbf{M}$ & Acromegaly; basal GH level $17 \mu \mathrm{g} / 1$ & IIO \\
\hline 5 & 68 & $\mathrm{~F}$ & Acromegaly; basal GH level $63 \mu \mathrm{g} /$ i & IIA \\
\hline 6 & 39 & $\mathrm{~F}$ & Cushing's disease & IIA \\
\hline 7 & 22 & $\mathbf{F}$ & Amen. + Gal; basal PRL level $130 \mu \mathrm{g} / 1$ & I \\
\hline 8 & 23 & $\mathbf{F}$ & Amen. + Gal; basal PRL level $1600 \mu \mathrm{g} / 1$ & IIIB \\
\hline 9 & 22 & $\mathbf{M}$ & Normal & IIB \\
\hline 10 & 33 & $\mathbf{M}$ & Normal & IIA \\
\hline 11 & 42 & $\mathbf{M}$ & Normal & IIA \\
\hline 12 & 48 & $\mathbf{M}$ & Normal & IIA \\
\hline 13 & 55 & $\mathbf{M}$ & Normal & IIA \\
\hline 14 & 58 & $\mathbf{M}$ & Normal & II0 \\
\hline 15 & 67 & $\mathbf{M}$ & Adrenal deficiency & IIIA \\
\hline 16 & 36 & $\mathbf{M}$ & Adrenal, gonadal, and thyroid deficiencies & IIB \\
\hline
\end{tabular}

*The given serum hormone concentrations are mean values and normal value for growth hormone (GH) is $<5 \mu \mathrm{g} / 1$ and for prolactin (PRL) is $<25 \mu \mathrm{g} / 1$ (female).

† Modification of Hardy's classification according to Baskin et al. ${ }^{4}$

$\ddagger$ Decreased to $11 \mu \mathrm{g} / 1$ after partial tumour necrosis one month before surgery.

Abbreviations: Amen. = amenorrhea, Gal. = galactorrhea

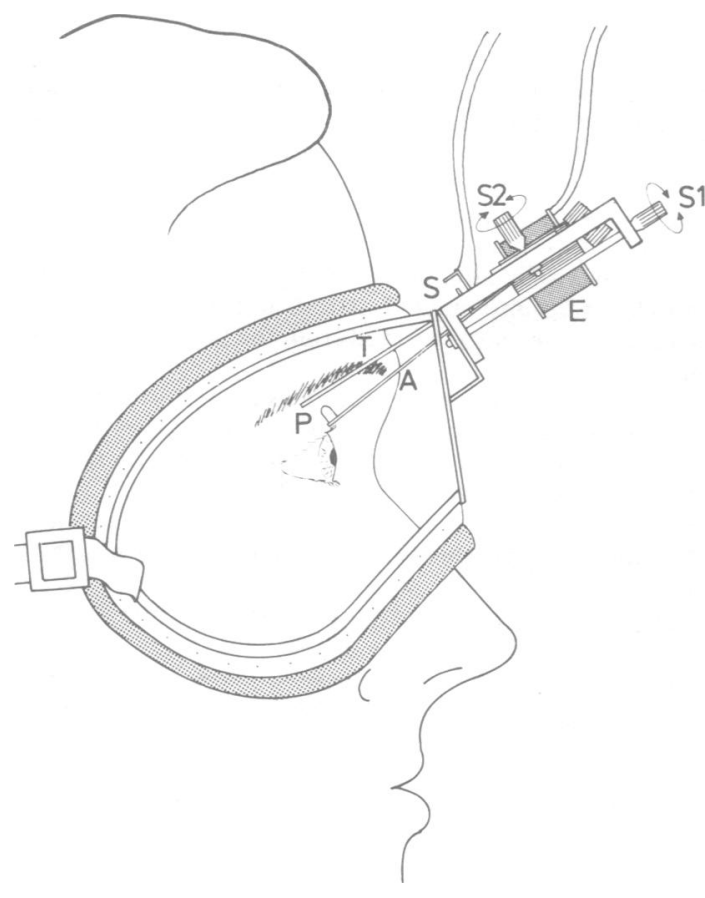

Fig 1 Diagram to illustrate the equipment for mechanical stimulation. The electromagnets $(E)$, one on each side, are individually adjusted to a symmetrical position so that the "tentacle" $(T)$ is just touching the skin below the eyebrow. This position is maintained by locking the screws (S1 and $S 2)$. Taps are delivered by driving the pellet $(P)$ on the tapping-arm $(A)$ through the hole in the "tentacle". $A$ trigger pulse to the recording unit is released by the interrupter-spring $(S)$ the instant the pellet contacts the skin.
Much raised $(++)$-tumourus tissue was squeezed through the dural incision, (b) Moderately raised $(+)-$ intrasellar tissue filled up the dural incision. (c) Not raised $(0)$ - the intrasellar content was easily explored after the dural incision.

\section{Facial reflex examination}

The test is based on the mechanically evoked early response (R1) of the recorded blink reflexes. The method has previously been described in detail.' Briefly, the equipment for mechanical stimulation consists of two identical electromagnetic miniature hammers attached to a pair of goggles which can be individually adjusted to get a firm and comfortable fit (fig 1). The region just below the eyebrow is tapped one side at a time. In all 60 to 100 stimuli in series of 10 or more taps at a frequency of $1 \mathrm{~Hz}$ are given on each side with a stop of at least $30 \mathrm{~s}$ between each series.

The evoked responses are recorded from the orbicularis oculi muscles by electromyographic technique using subdermal needle electrodes. They are symmetrically placed with one electrode in the eyebrow and the other above the motor point at the lateral canthus of the eye on each side. The bicanthal electrodes are adjusted so that there is a sharp take-off of the evoked response. The ground electrode is a disc on the neck. The muscle action potentials are amplified and displayed on a double-beam oscilloscope (Tektronix RM 564). In order to get an easy and objective measurement of R1 latency an electronic equipment based on pattern recognition technique is used. $\mathrm{R} 1$ latency is measured from the instant the hammer contacts the skin to the initial deflection of the discharge. The statistical analysis is performed on line by a programmed calculator (Compucorp 445 Statistician) and the evoked responses and their latencies are individually displayed on a fibreoptic oscilloscope (Medelec) (fig 2).

The mean latency and latency distribution (the standard deviation) of $\mathrm{R} 1$ are used to describe the conduction along the reflex path consisting of the first trigeminal division, the 


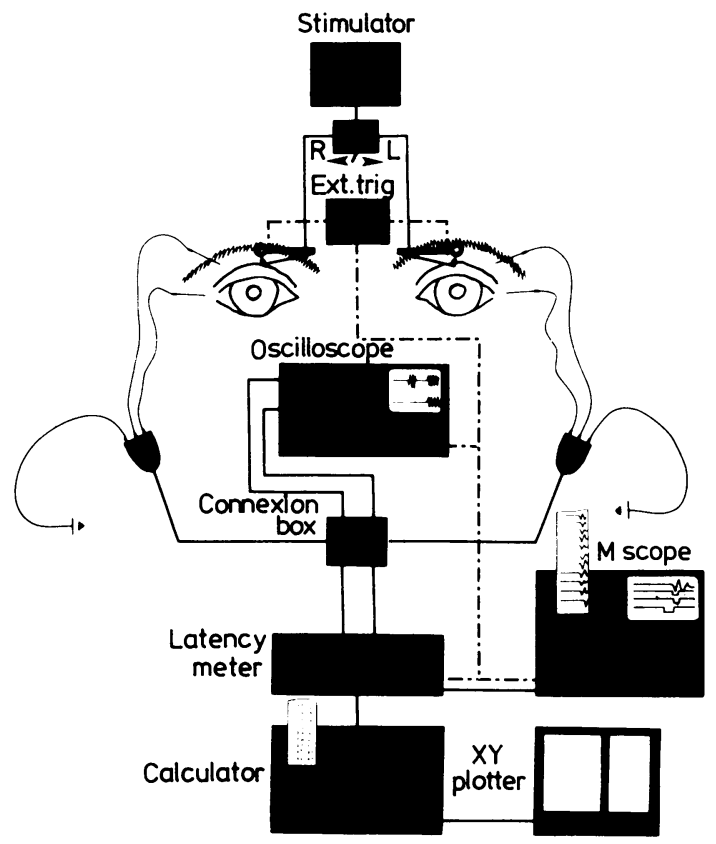

Fig 2 Diagram to illustrate the equipment for facial reflex examination.

oligosynaptic connection in the brain stem between the trigeminal nerve and the facial motornucleus, and the facial nerve. The mean latency is based on latencies of 60-100 repetitively evoked responses on each side, exluding the first response in each series as it may be divergent in appearance. The difference between the mean latency on the right and left sides is expressed in mean latency difference.

Reference values have been obtained in a control study. The reference interval of the latency difference is $0.25 \mathrm{~ms}$ $(p<0.05)$ and a value exceeding $0.25 \mathrm{~ms}$ has been estab-

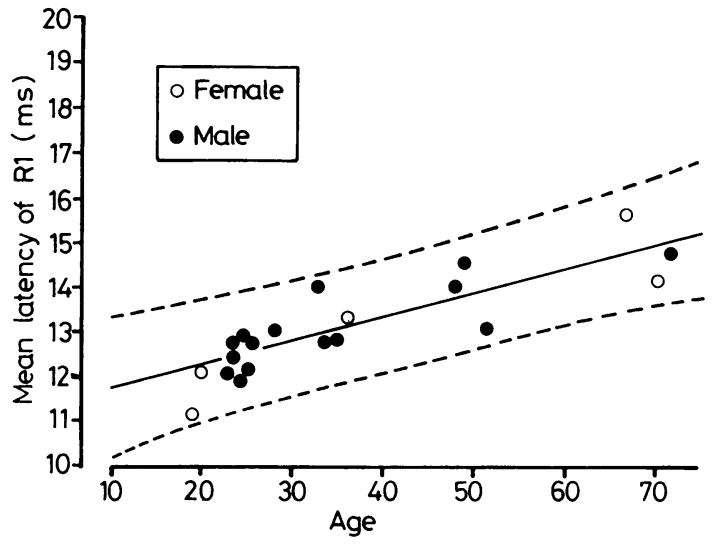

Fig 3 RI latency as a function of age. The regression line, $y=11.14+0.05 \times$ age $(n=20)$, and the reference limits $(p<0.05)$ are indicated.

lished as abnormal. The reference interval of the latency distribution is $0.49 \pm 0.15 \mathrm{~ms}(\mathrm{p}<0.05)$. Values above the upper reference limit, $0.64 \mathrm{~ms}$, indicate disturbances in the central reflex transmission and/or in the afferent input. Values below the lower reference limit, $0.34 \mathrm{~ms}$, indicate a central hyperexcitability of R1. It should be pointed out that $\mathrm{R} 1$ latency is age dependent and follows the regression line described by the equation $y=11 \cdot 14 \pm 0.05 \times$ age (ms), which is shown in fig 3 together with its reference limits $(\mathrm{p}<0.05)$.

The electromyographic recordings from orbicularis oculi muscles were also studied at rest and during contraction with the electrodes preserved from the facial reflex examination.

The facial reflex examination was performed shortly before the operation in all patients and it was repeated postoperatively in 10 patients. No patient was receiving drugs known to influence the test. The mechanical stimulation was painless and the procedure could be done with no discomfort or apprehension of the patient who was resting

Table 2 Mean latency $\left(M L_{R}\right.$ and $\left.M L_{L}\right)$, latency distribution $(S D)$, and mean latency difference $(M L D)$ of $R I$ in 16 patients with pituitary fossa lesions

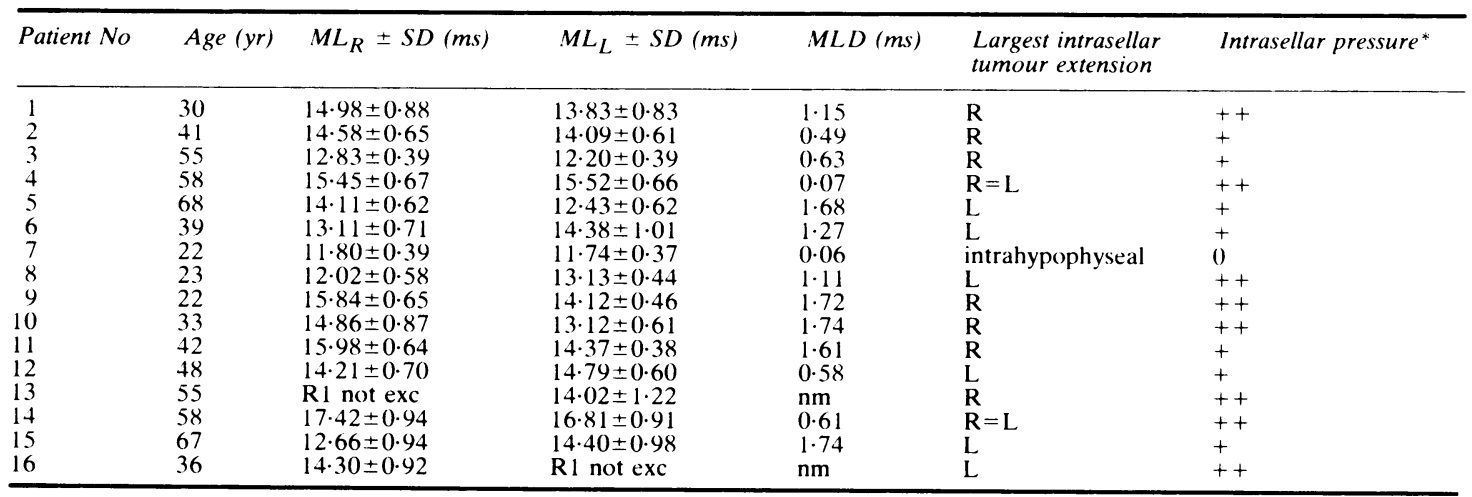

*For classification see text. $++=$ much increased, $+=$ moderately increased, $0=$ not increased.

Abbreviations: $\mathrm{R}=$ right side, $\mathrm{L}=$ left side, exc $=$ excitable, $\mathrm{nm}=$ not measurable. 
Table 3 Mean latency $\left(M L_{R}\right.$ and $\left.M L_{L}\right)$ and latency distribution (SD) of $R 1$ and the decrease in $R 1$ latency after removal of the tumour in nine patients

\begin{tabular}{|c|c|c|c|c|}
\hline Patient No & Age (yr) & $\begin{array}{l}M L_{R} \pm S D \\
M L_{L} \pm S D(m s)\end{array}$ & $\begin{array}{l}\text { Decrease in } M L_{R} \\
\text { Decrease in } M L_{L}(\mathrm{~ms})\end{array}$ & Time after tumour removal \\
\hline 2 & 41 & $\begin{array}{l}14 \cdot 10 \pm 0.49 \\
13.97 \pm 0.49\end{array}$ & $\begin{array}{l}0 \cdot 48 \\
n s\end{array}$ & 1 month \\
\hline 3 & 55 & $\begin{array}{l}12.03 \pm 0.46 \\
11.62 \pm 0.57\end{array}$ & $\begin{array}{l}0.80 \\
0.58\end{array}$ & 2 months \\
\hline 4 & 58 & $\begin{array}{l}14.53 \pm 0.56 \\
14.48 \pm 0.57\end{array}$ & $\begin{array}{l}0.92 \\
0.92 \\
1.04\end{array}$ & 2 months \\
\hline 5 & 68 & $\begin{array}{l}14.07 \pm 0.55 \\
12.67 \pm 0.60\end{array}$ & $\begin{array}{l}1.04 \\
\text { ns } \\
\text { ns }\end{array}$ & 2 months \\
\hline 6 & 39 & $\begin{array}{l}12.75 \pm 0.62 \\
12.41 \pm 0.58\end{array}$ & $\begin{array}{l}0.36 \\
0.97\end{array}$ & 5 months \\
\hline 8 & 23 & $\begin{array}{l}11.82 \pm 0.45 \\
11.72 \pm 0.52\end{array}$ & $\begin{array}{l}\text { ns } \\
1.41\end{array}$ & 1 week \\
\hline 12 & 48 & $\begin{array}{l}14.14 \pm 0.61 \\
14.23 \pm 0.65\end{array}$ & $\begin{array}{l}\text { ns } \\
0.56\end{array}$ & 2 months \\
\hline 14 & 58 & $\begin{array}{l}16.93 \pm 0.74 \\
14.88 \pm 0.60\end{array}$ & $\begin{array}{l}0.49 \\
1.93\end{array}$ & 6 months \\
\hline 16 & 36 & $\begin{array}{l}14 \cdot 04 \pm 0 \cdot 71 \\
15 \cdot 34 \pm 1 \cdot 13\end{array}$ & $\begin{array}{l}\mathrm{ns} \\
\mathrm{nm}\end{array}$ & 3 months \\
\hline
\end{tabular}

Abbreviations: $n s=$ not significant $(\mathrm{p}>0.05-$ Student's $\mathrm{t}$ test $), \mathrm{nm}=$ not measurable; $\mathrm{R} \mathrm{I}$ was not excitable before surgery.

on a comfortable bed. The tapping was increased in strength until the initial part of R1 had equal appearance from the second discharge and onwards in series of repetitively evoked responses at $1 \mathrm{~Hz}$. This strength of stimulus was then kept equal on both sides.

\section{Results}

Impaired transmission along the trigemino-facial pathway was present on one or both sides in all except one patient (Patient 7). Her tumour was small, an intrahypophyseal microadenoma. The tumours of the other patients were substantially larger and they encroached on the walls to the cavernous sinuses.

The individual results of the preoperative facial reflex examination and the intraoperative findings concerning intrasellar pressure and lateral tumour extension are shown in table 2 . R1 was delayed or abolished on the side of the largest lateral tumour extension in 12 of 13 patients. $R 1$ was delayed on both sides in two patients (Patients 4 and 14) whose R1 latencies obviously exceeded the expected level for their ages (see fig 3). Their tumours were symmetrically located within the sellae and pushed away the walls of the cavernous sinuses on both sides.

The latency distribution of $\mathrm{Rl}$ was increased above the upper reference value, $0.64 \mathrm{~ms}$, in 11 of 15 patients with laterally extending tumours. Abnormal latency distribution on both sides was found in seven patients and in five of them the intrasellar pressure was much raised.

The individual test results and the change after the removal of the tumours are shown in table 3 and for Patient 11 in fig 4.

A significant decrease in R1 latency after operation on one or both sides was observed in all except one patient (Patient 5). The decrease was greater on the tumour side than on the opposite side in patients with tumours of asymmetrical intrasellar location. Recovery in R1 latency was complete in four patients (mean latency difference less than $0.25 \mathrm{~ms}$ ). The latency distribution was still increased on one or both sides in two patients (Patient 14 and 16). Both

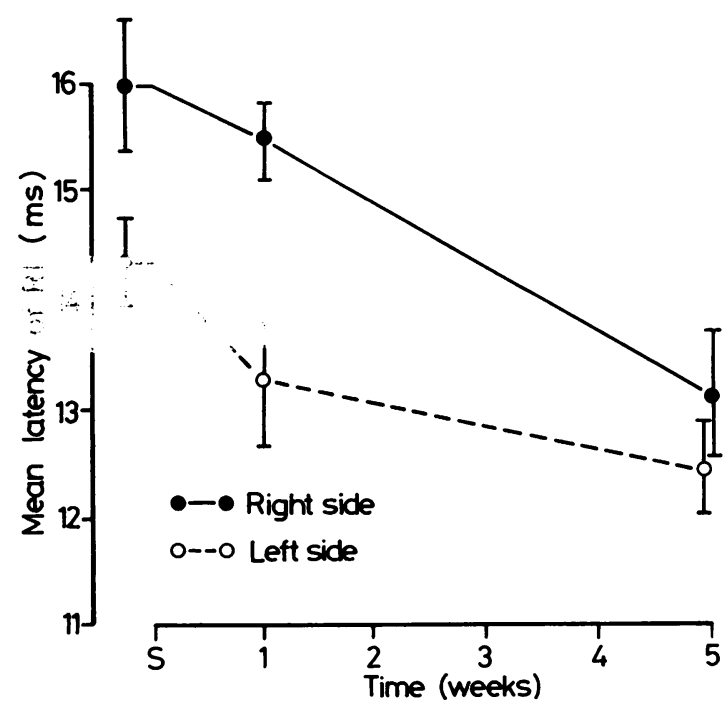

Fig 4 Change in $R 1$ latency after transsphenoidal removal of a non-secreting pituitary adenoma in Patient 11. His tumour-grade was IIA and there was a lateral intrasellar tumour extension on above all the right side. Recovery in $R I$ latency was shown on both sides but it was not complete 5 weeks after the tumour removal. The observed decrease in $R 1$ latency was $2.8 \mathrm{~ms}$ on the right side and $1.9 \mathrm{~ms}$ on the left side. 
presented incomplete restoration of R1 latency.

The electromyographic recordings before and after operation did not show signs of denervation of the orbicularis oculi muscles in any patient.

\section{Discussion}

The anatomical relations of the cavernous sinus have been subject of several studies. ${ }^{10-13}$ It has recently been shown that the oculomotor and trochlear nerves, and the first trigeminal division are not embedded in the lateral wall of the cavernous sinus but enveloped in thin sheets which are loosely attached to the inner surface of the dural wall. ${ }^{14}$ Accordingly, these cranial nerves are poorly protected against compression from a medially situated space-occupying lesion. The first trigeminal division passes through the inferior part of the cavernous sinus with the abducens nerve and the internal carotid artery on its medial side. The carotid artery is mobile within the space of the cavernous sinus except at its anterior portion where it is in contact with bone. A sellar tumour encroaching on the flexible wall to the cavernous sinus may, therefore, compress the first trigeminal division either directly or by the laterally displaced cavernous carotid.

Sudden intrasellar expansion as in acute necrosis of pituitary tumours may produce a cavernous sinus syndrome with involvement of the first trigeminal division and the ocular motor nerves. ${ }^{15-18}$ Trigeminal symptoms are rare in patients with slowly growing pituitary tumours. ${ }^{18}$ This fact does not exclude the presence of trigeminal nerve involvement. Subclinical entrapment of the trigeminal nerve was not an uncommon finding in patients with acoustic tumours. $^{?}$

Clinical, radiographic, and electromyographic examination did not show involvement of the brain stem and the facial nerve in any patient of the present study. Therefore, the observed $\mathrm{R} 1$ delay may be ascribed to involvement of the first trigeminal division due to the proved encroachment on the cavernous sinus. R1 was delayed or abolished in all patients with laterally extending sellar tumours and raised intrasellar pressure but R1 latency was not disturbed in the patient with a pituitary microadenoma. Recovery in $\mathrm{R} 1$ latency was observed after removal of secreting as well as non-secreting pituitary adenomas and also after removal of a craniopharyngioma. Therefore, the decrease in $\mathrm{R} 1$ latency seems to be due to release of pressure on the first trigeminal division and not to restoration or improvement of endocrine dysfunction. The mean latency difference was normalised in the younger patients but recovery was not complete in two patients with substantially impaired conduction probably due to certain degree of permanent nerve damage. The oldest patient of the series, Patient 5, did not show any postoperative restoration of $\mathrm{R} 1$ latency. She had had partial tumour apoplexy and her tumour was necrotic on the side of the R1 delay and it seems likely that a larger lateral tumour extension had been present on that side. These circumstances may explain the discrepancy between the side of $\mathrm{R} 1$ delay and the demonstrated lateral tumour extension at surgery.

In conclusion, the present study has shown that sellar tumours may become large without producing neurological signs of the involved trigeminal nerve. The tumour impact on the first trigeminal division can be disclosed by the facial reflex examination provided that involvement of the brain stem and facial nerve is not present. The lateral extension of sellar tumours seems to be a common but not always noticed feature in patients with lesions enlarging the pituitary fossae.

\section{References}

' Syvertsen A, Haughton VM, Williams AL, Cusic JF. The computed tomographic appearance of the normal pituitary gland and pituitary microadenomas. Radiology 1979; 133:385-91.

${ }^{2}$ Banna M, Baker HL, Houser OW. Pituitary and parapituitary tumours on computed tomography. $\mathrm{Br} J$ Radiol 1980;53:1123-43.

${ }^{3}$ Jung RT, White MC, Bowley NB, Bydder G, Mashiter $\mathrm{K}$, Joplin GF. CT abnormalities of the pituitary in hyperprolactinaemic women with normal or equivocal sellae radiologically. Br Med J 1982;285: 1078-81.

${ }^{4}$ Théron J, Chevalier D, Delvert M, Laffont J. Diagnosis of small and micropituitary adenomas by intracavernous sinus venography. A preliminary report. Neuroradiology 1979;18:23-30.

${ }_{5}^{5}$ Kugelberg E. Facial reflexes. Brain 1952; 75:385-96.

${ }^{\circ}$ Lindquist C, Marrtensson A. Mechanisms involved in the cat's blink reflex. Acta Physiol Scand 1970;80:14959.

' Bynke O. Facial reflex examination. A clinical and neurophysiological study on acoustic tumours and brain displacement at the tentorial notch. Acta Neurol Scand 1980;62:Suppl 76:1-127.

${ }^{8}$ Hardy J. Transsphenoidal surgery of hypersecreting pituitary tumours. In: Kohler PO, Ross GT, eds. Diagnosis and Treatment of Pituitary Tumors. Amsterdam: Exerpta Medica. International Congress Series No. 303. 1973:179-94.

${ }^{y}$ Baskin DS, Boggan JE, Wilson CB. Transsphenoidal microsurgical removal of growth hormone-secreting pituitary adenomas. $J$ Neurosurg 1982;56:634-41.

${ }^{10}$ Parkinson D. A surgical approach to the cavernous portion of the carotid artery. $J$ Neurosurg 1965;23:474 83.

" Patouillard P, Vannenville G. Les parois du sinus caver- 
neux. Neurochirurgie 1972;18:551-60.

12 Harris FC, Rhoton AL. Anatomy of the cavernous sinus. A microsurgical study. J Neurosurg 1976;45:160-80.

${ }^{13}$ Rhoton AL Jr, Hardy DG, Chambers SM. Microsurgical anatomy and dissection of the sphenoid bone, cavernous sinus and sellar region Surg Neurol 1979;12:63104.

${ }^{i t}$ Umansky F, Nathan $H$. The lateral wall of the cavernous sinus. With special reference to the nerves related to it. J Neurosurg 1982;56:228-34. is Foix C. Syndrome de paroi externe des sinus caverneux. Rev Neurol (Paris). 1922; 29:827-32.

${ }^{16}$ Rovit RL, Fein JM. Pituitary apoplexy: a review and reappraisal. J Neurosurg 1972;37:280-88.

${ }^{17}$ Robert CM Jr, Feigenbaum JA, Stern WE. Ocular palsy occurring with pituitary tumors. J Neurosurg 1973; 38: 17-19.

" Wray SH. Neuro-ophthalmologic manifestations of pituitary and parasellar lesions. In: Clin Neurosurg 1976;24: 107-17. 